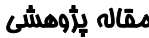

\section{بررسى باور به جايكاه درونى كنترل سلامت وارتباط آن با خودكار آمدى جهت انجام مامو كر افى درزنان با سابقه خانوادكى سرطان بـتان}

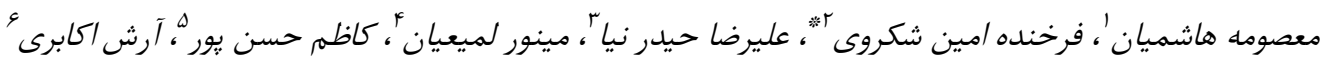

'دانشجوى دكترى آموزش بهداشت دانشكاه تربيت مدرس، ديار تمان آموزش بهداشت، تهران، ايران

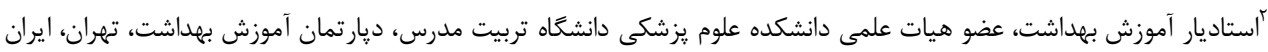

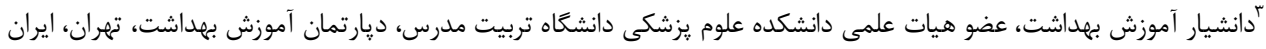

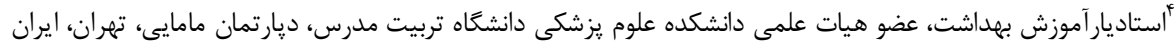

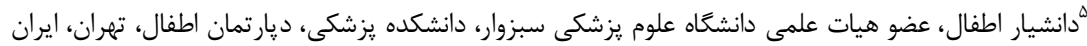

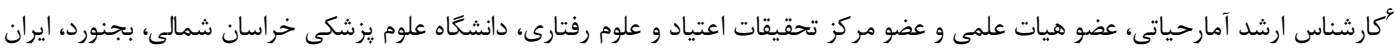

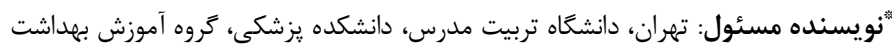

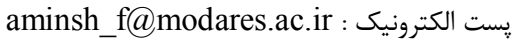

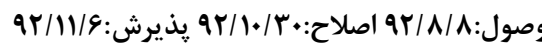

جִكيده

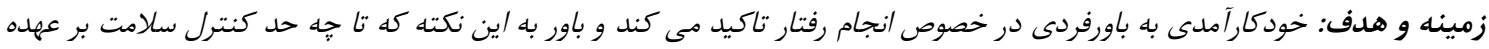

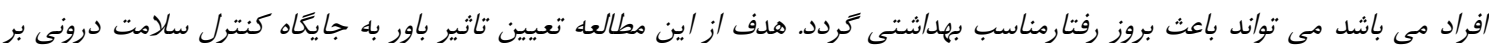

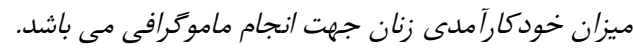

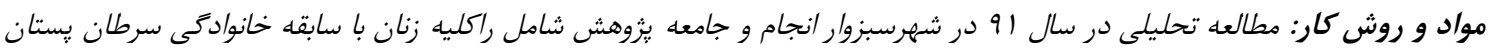

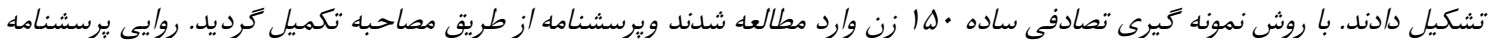

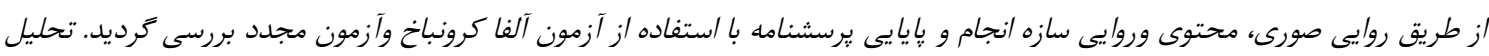

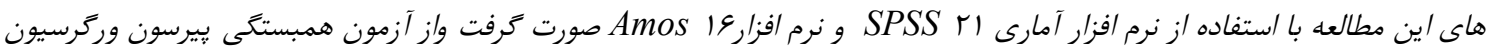

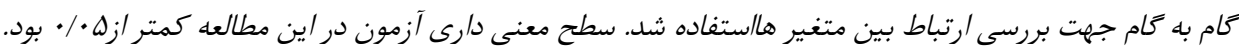

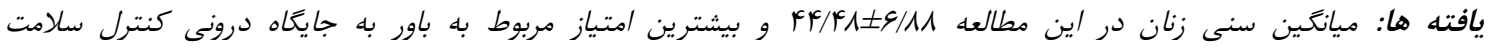

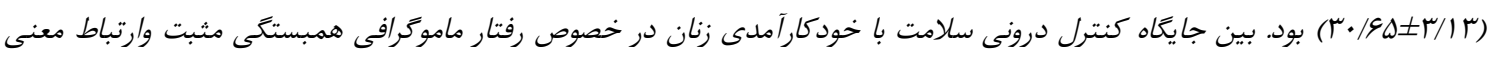

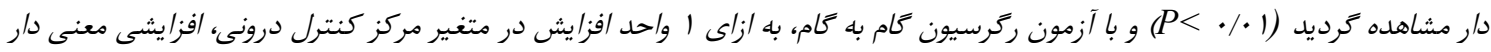

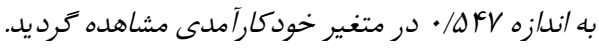

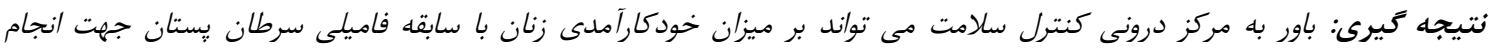

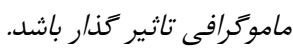
واثه هاى كليدى: خودكار آمدى، سرطان بستان، جايكاه كنترل سلامت، ماموكرافى بانى

بيمارى قرار دارد [ [1]. در ايران متاسفانه اين بيمارى شايع مقدمه

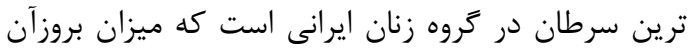
سرطان پستان شايع ترين نوع سرطان بعد از سرطان

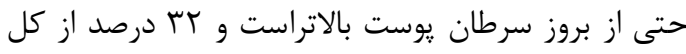

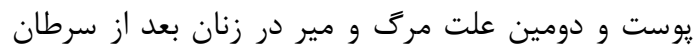

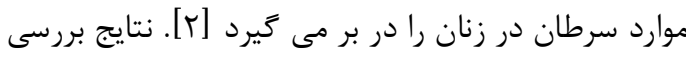

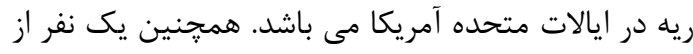

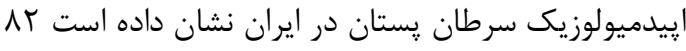

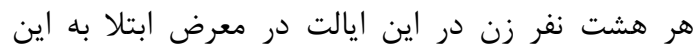


مفهوم مركز كنترل يكى از مباحث مهم روانشناسى است كه براى نخستين بار توسط روتر مطرح شد و اشاره به مبه

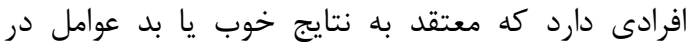

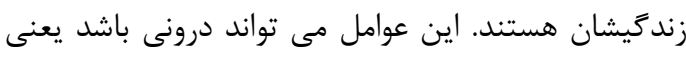

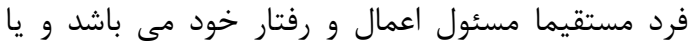
بيرونى باشد يعنى فرد معتقد به عوامل محيطى، نيروهاى

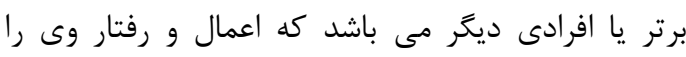

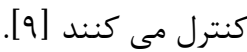

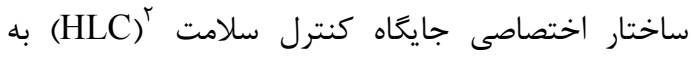

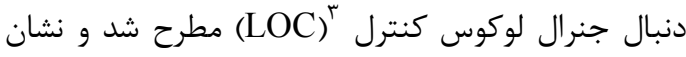
دهنده ى درجه اعتقاد فرد به عوامل كنترل كننده درونى

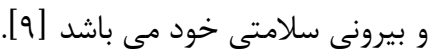

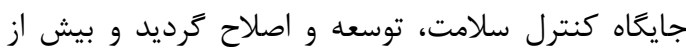

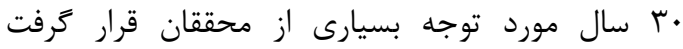
[1/، [1]. طبق اين تئورى افرادى كه معتقد به مركز

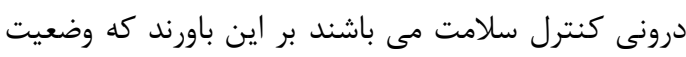

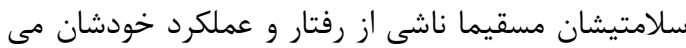

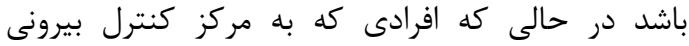

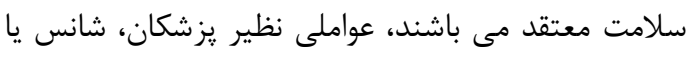
بخت و اقبال و سرنوشت را مسئول سلامتى خود مى دانند

. [1 T ]

مفهوم خودكارامدى نيز عبارتست از اعتمادى كه شخص

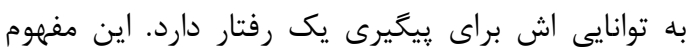

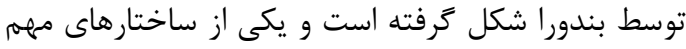

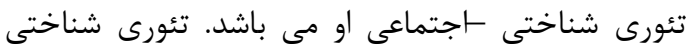

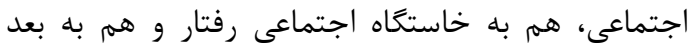

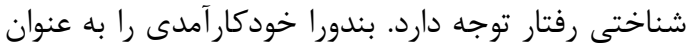
يك مفهوم مركزى مطرح كرده كه به ادراك توانايى انجام

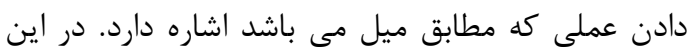
ديدكاه رفتار تحت تاثير نيروهاى اجتماعى است ولى دئ نحوه

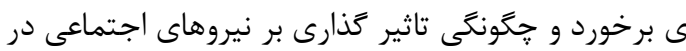

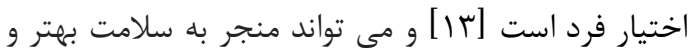
موفقيت بالاتر گردد. در صورتى كه مردم بر اين باور باشند

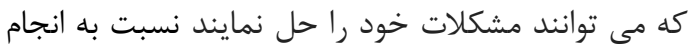

\section{2 -Health Locus of Control} 3- Locus of Control
درصد موارد تشخيص اين بيمارى در مراحل ييشرفته آن

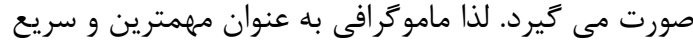

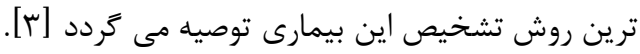

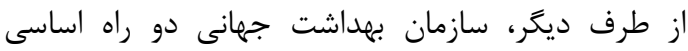
يِيشَيرى از سرطان يستان را آموزش و ماموكرافى اعلام

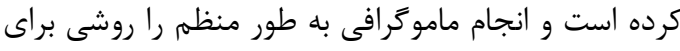

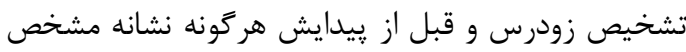

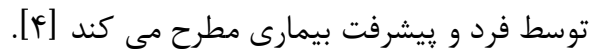

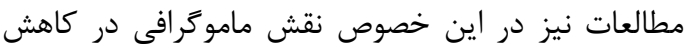
ميزان مرك و مير را مورد تاكيد قرار داده اند، از جمانه

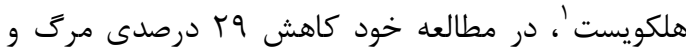

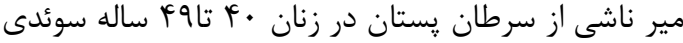

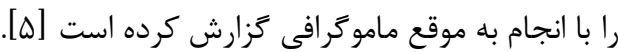
از سوى ديكر عوامل خطر متعددى در بروز سرطان يستان نقش دارند، از جمله مى توان به عواملى نظير: سن، جنس،

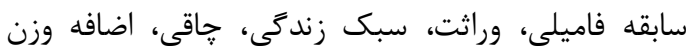

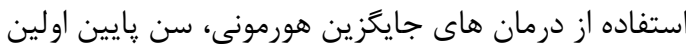

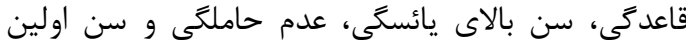

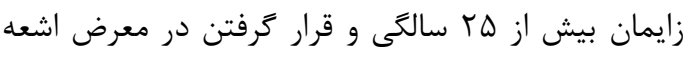

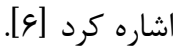
بنابراين ريسك فاكتورهاى اين بيمارى به دو دسته قابل تغيير و غير قابل تغيير تقسيم مى شود در اين ميان سابقه

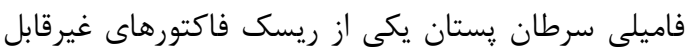
تغيير اين بيمارى محسوب مى شود، خطر ابتلا به سرطان يستان در اين زنان در مقايسه با زنان بدون سابقه فاميلى

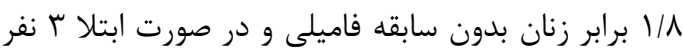

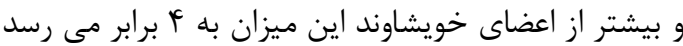

عوامل متعددى بر اتخاذ رفتاريشيشيرى كننده ى سرطان يستان در زنان تاثير تذار مى باشد، در اين خصوص

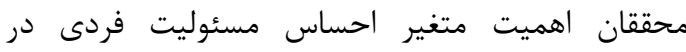
رفتارهاى غربالكرى سرطان يُتان را مورد تاكيد قرار داده

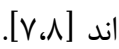
بنابراين باور زنان به اين نكته كه تا جه حد كنترل سلامت

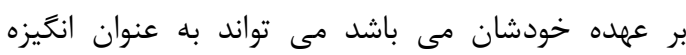

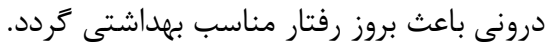

\section{1-Hellquist}


صورتى كه فرد مبتلا در خانواده در سنين قبل از يائسكى دجار سرطان پِتان شده باشد، ·1 سال كمتر از سن

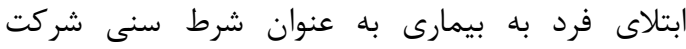

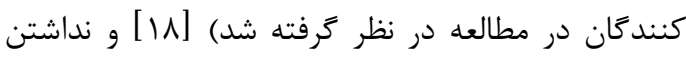
توده مشكوك در ماموكرافى يا سونو يستان ها بوده است.

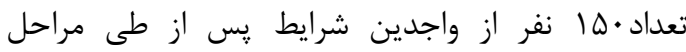
ملاحظات اخلاقى يعنى مواردى نظير اطمينان از محرمانه

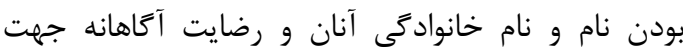
شركت وتكميل يرسشنامه هاى مطالعه با توجه به توضيح به شركت كنند عدم ادامه همكارى در مطالعه هر زمان كه تمايل داشته

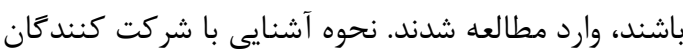
با توجه به شناسايى فرد مبتلا در خانواده و دعوت ازآنان از طريق تماس تلفنى صورت گرفت.

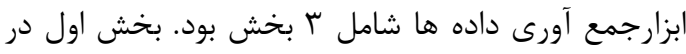
خصوص مشخصات جمعيت شناختى شركت كنندكان و بخش دوم شامل قياس جند وجهى جايگاه كنترل سلامت والستون بود كه خود از ץ زير مقياس تشكيل شده است. ا - جايعاه درونى كنترل سلامت ب (IHLC) نشان دهنده ى درجه اعتقاد فرد به اين موضوع كه عوامل

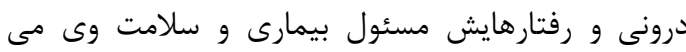
باشد

r- كنترل سلامت توسط نيروهاى ديگر نشان دهنده ى درجه اعتقاد فرد به اين موضوع كه سلامت او به وسيله افراد ديخر تعيين مى دى شود r-كنترل سلامت توسط شانس ${ }^{r}$ (CHLC)

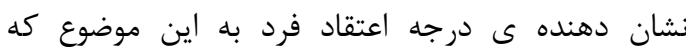
سلامت او ناشى از شانس، بخت وهن و اقبال مى دى باشد. همجنين اين مقياس شامل ب فرم A و B و C مى بـ باشد. فرم هاى A و B موازى بوده و معى توان از يكى ازئ از آنان

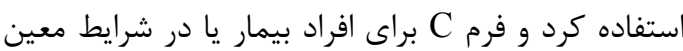

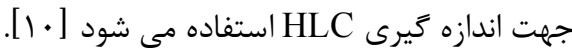

2 -Internal Health Locus of Control 3 -Power Health Locus Control 4 -Chance Health Locus Control
كار تمايل بيشترى پييدا كرده و احساس تعهد بيشترى

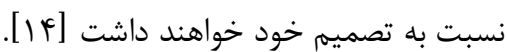

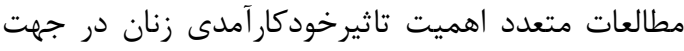
حفظ و ارتقا سلامتى خود با انجام ماموَّرافى و غربالكَرى

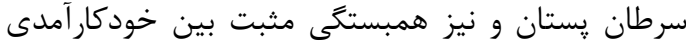

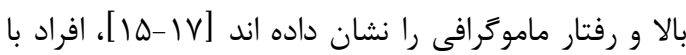

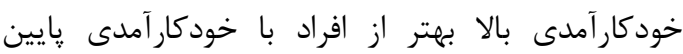

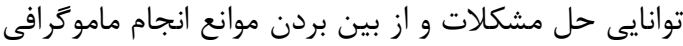

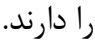
لذا، باور افراد به اين نكته كه مسئوليت فردى در قبال حفظ و ارتقا سلامت امرى بسيار مههم مى باشد و اعتقاد به به بـان جايكاه درونى كنترل سلامت به عنوان إنسان تعيين كننده

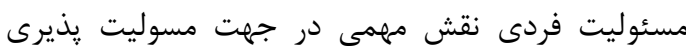

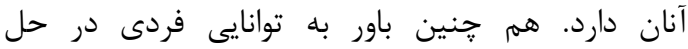

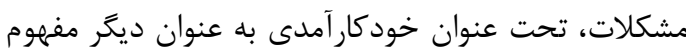

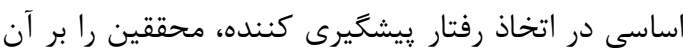
داشت تا ارتباط بين اين دو مفهوم را بررسى نمايند تا در درئر صورت وجود ارتباط در جهت تقويت جايخاه درونى كنترل

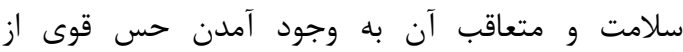
خودكارآمدى، مداخلات مناسب آموزشى را به عمل آورند.

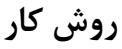
اين مطالعه مقطعى تحليلى در سال | |جسا در شهرستان

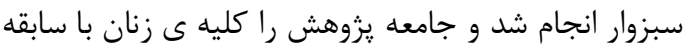
خانوادگى سرطان پستان تشكيل داد وادند. تعداد بيماران سرطانى شناخته شده، در سطح شهرستان

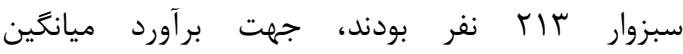

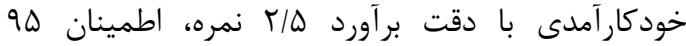

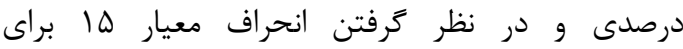
خودكارآمدى، حجم نمونه لازم براى اين مطالعه كه نفر نفر

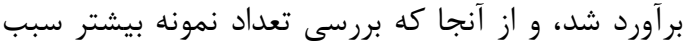

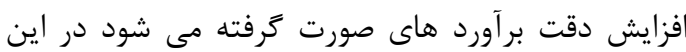

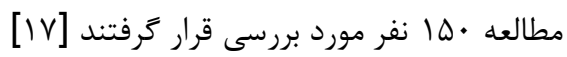
معيار ورود به مطالعه، عضو مونث و درجه اول خان خرانواده (مادر، خواهر و دختر فرد مبتلا )، سن هاسال و بالاتر (

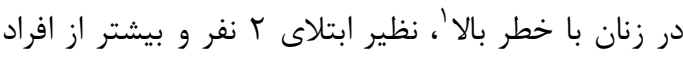

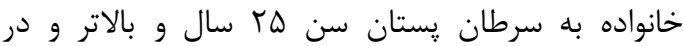

\section{1 -High risk}


محتوى (CVI)'استفاده شد. نمره مقياس بالاتر از V9/. به عنوان روايى محتوايى مقياس مورد تاييد قرار كرفت

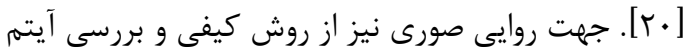

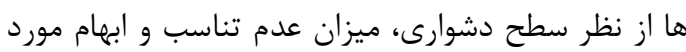

$$
\text { بر سى قرار كرفت. }
$$

همجنين جهت روايى سازه، از تحليل عاملى تاييدى و از

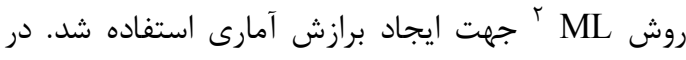

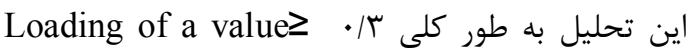
مورد قبول مى باشد و ارزيابى برازش مناسب مدل مدل در صورتى قابل قبول است كه comparative ( CFI ( normed fit index ) NFI ( ) ئ (incremental fit index) IFI ،(fit index

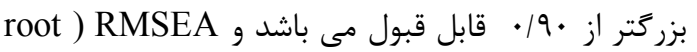
كمتر از (mean square error of approximation

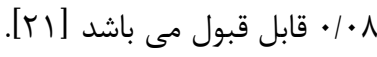
جهت بررسى پايايى مقياس خودكارآمدى و و تعيين

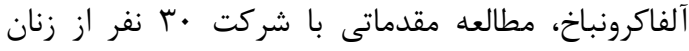
واجد شرايط مطالعه كه در مطالعه اصلى شركت نداشتند،

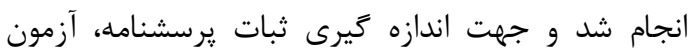

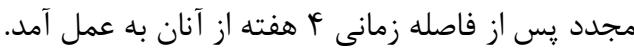

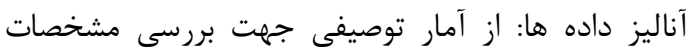

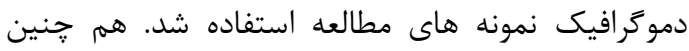
جهت بررسى ارتباط بين متغير هاى جايياه كنترل

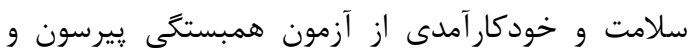

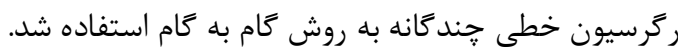
تحليل هاى اين مطالعه با استفاده از نرم افزار آمارى

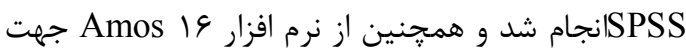

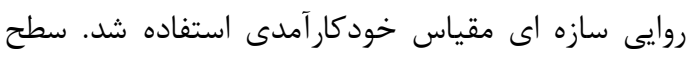

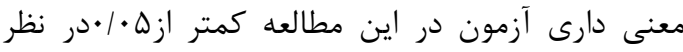

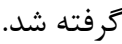

يافته ها

ميانكين سنى شركت كنند كان در يزوهش سال با حداقل سن مئ و حداكثر سن 99 سال بوده است.

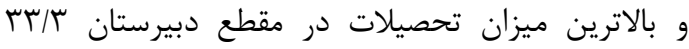

1- Content Validity Index

2 -Maximum Likelihood
در اين مطالعه از فرم Aجهت جمع آورى داده ها استفاده

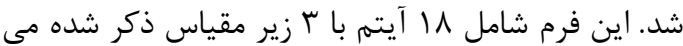

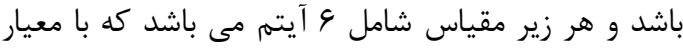

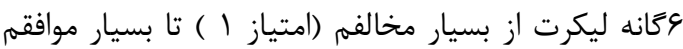

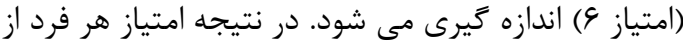

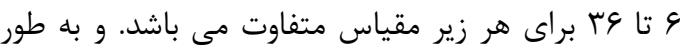
جداكانه برآورد مى كردند [11] شامل مقياس خودكار آمدى جميون جهت انجام ماموكر افى

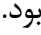
اين مقياس شامل • ا آيتم مى باشد كه هر يك از آيتم ها با مقياس ليكرت ها قسمتى از به احتمال خيلى كم (امتياز

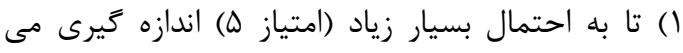

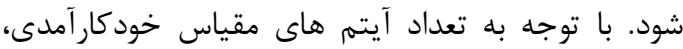

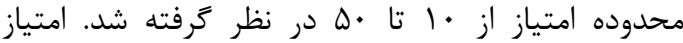
بيشتر نشان دهنده خودكارآمدى بالاتر و احتمال بيشتر

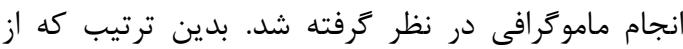

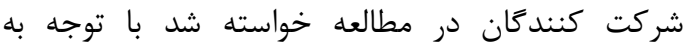
احساسى كه در مورد جملات خوانده شده دارند بهرترين

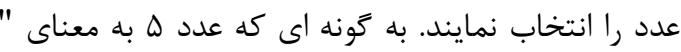
بسيار موافق" و عدد ا به معناى " بسيار مخالف" مى الفى كائد

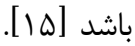
روايى و يايايى ابزار مقياس جايگاه جند وجهى سلامت براى نخستين بار در ايران توسط مشكى و همكارانش

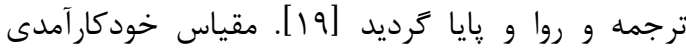
جمييون نيز بعد از كسب مجوز از تهيه كنينده اصلى اين

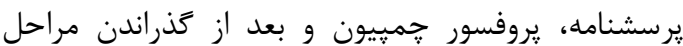

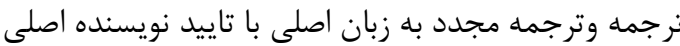
و با كذراندن مراحل زير رواو و پايا كرديد.

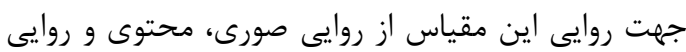
سازه استفاده شد. بدين ترتيب كه جهت روايى محتوى از

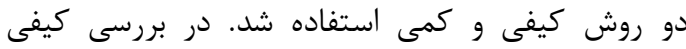

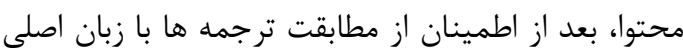

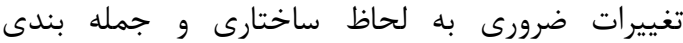
يرسشنامه ها با صلاحديد پانل خبركان ( 1 نفر متخصص

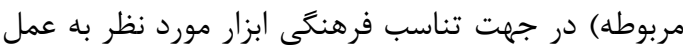

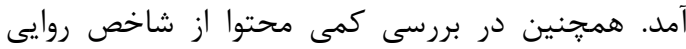


FF/VF

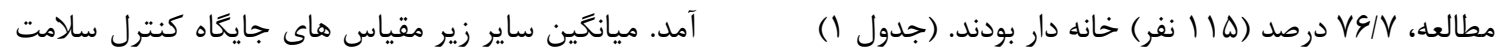

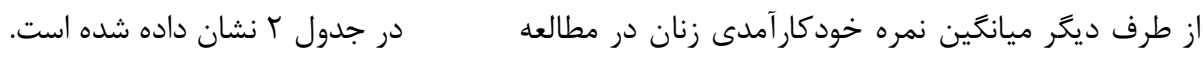
جدول ا: توزيع فراوانى متغيرهاى دموكرافيك شركت كنند كان در يزوهش ( • N=ID)

\begin{tabular}{|c|c|c|}
\hline (درصد) فراوانى & زير كروه & 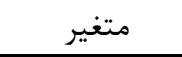 \\
\hline$G(t)$ & $r \Delta-r \omega$ & 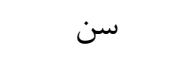 \\
\hline $1 \cdot 9(V \cdot / V)$ & $r \Delta-r \Delta$ & \\
\hline$r \&(I V / \Gamma)$ & $\varphi \Delta-\Delta \Delta$ & \\
\hline $\mathbb{I r}(\Lambda)$ & بزر تمتر از هصه & \\
\hline$\|(\Lambda / V)$ & 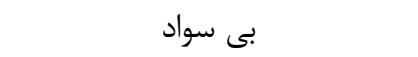 & تحصيلات \\
\hline$V \varphi(\Delta \cdot / V)$ & ابتدايى وراهنمايى & \\
\hline$\Delta \cdot(\Pi / \Gamma)$ & دبيرستان & \\
\hline$\|(V / \Gamma)$ & دانشخاهى & \\
\hline $110(V \& / V)$ & خانه دار & 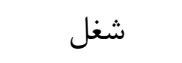 \\
\hline $\mathbb{I r}(N / \mathrm{V})$ & 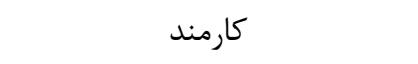 & \\
\hline$r(r)$ & كارگر & \\
\hline $19(1 Y / V)$ & ساير موارد & \\
\hline $\operatorname{lrg}(9 \cdot / V)$ & متاهل & وضعيت تاهل \\
\hline$r(r)$ & 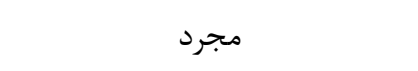 & \\
\hline$r(r)$ & بيوه & \\
\hline$\Lambda(\Delta / \Gamma)$ & مطلقه و جدا از هم & \\
\hline FN (Tr) & كمتر از ... . أتومان & وضعيت در آمد \\
\hline$V \varepsilon(\Delta \cdot / V)$ & 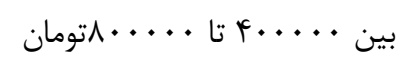 & \\
\hline$M(\mid r)$ & 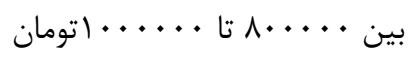 & \\
\hline$\wedge(\Delta / \Gamma)$ & بيشتر از . . . . . اتومان & \\
\hline$\Lambda T(\Delta F / V)$ & 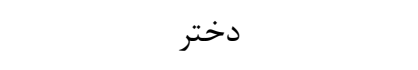 & 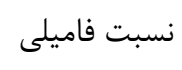 \\
\hline$\Delta q(\Gamma q / \Gamma)$ & خواهر & \\
\hline $9(9)$ & مادر & \\
\hline
\end{tabular}


جدول r: توزيع ميانكين، انحراف معيار امتياز زير مقياس هاى جايگاه كنترل سلامت و خودكار آمدى

\begin{tabular}{|c|c|c|c|c|}
\hline حداكثر نمره & حداقل نمره & انحراف معيار & ميانگين & زير مقياس \\
\hline rq & IV & سוץ & $r \cdot 190$ & باور درونى \\
\hline m & $\wedge$ & 9199 & $19 / 99$ & باور به شانس \\
\hline re & if & $f / \cdot \Lambda$ & $r \cdot / r t$ & باور به نيرو هاى ديخر \\
\hline$p q$ & Tr & N/VD & MF/VF & خود كار آمدى \\
\hline
\end{tabular}

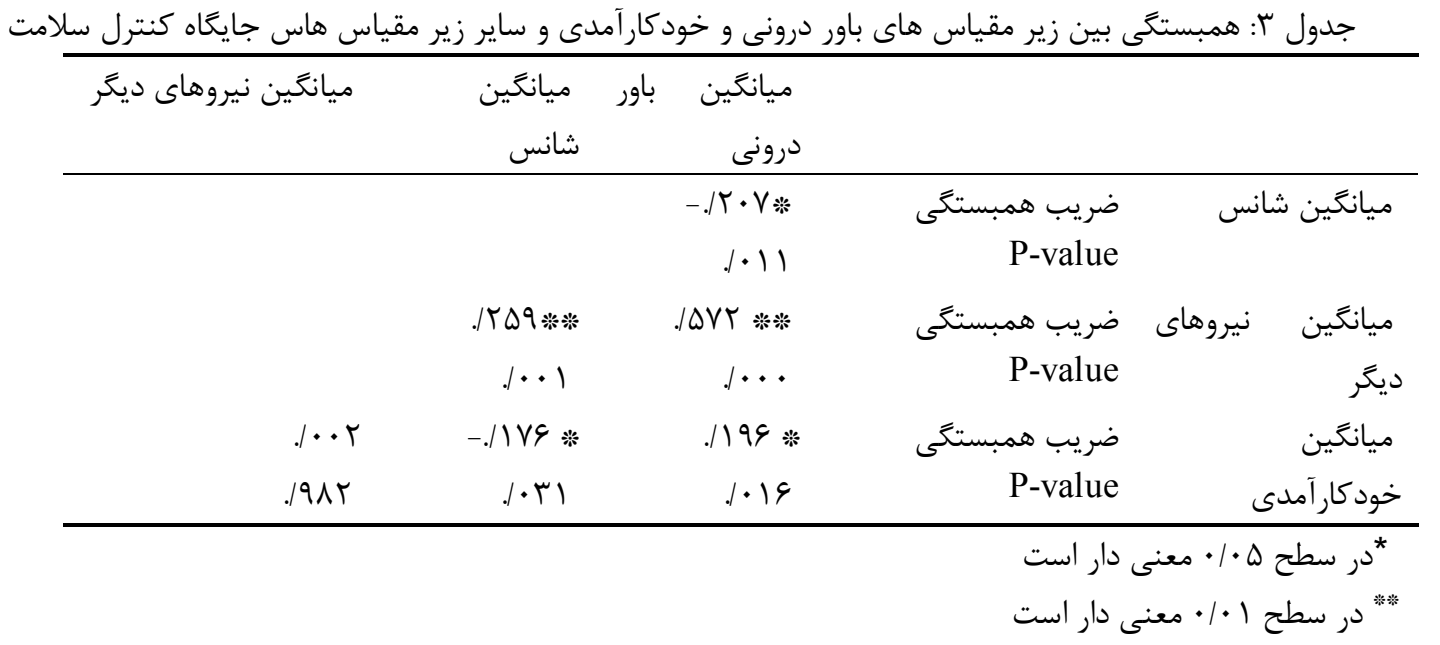

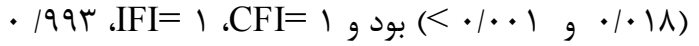

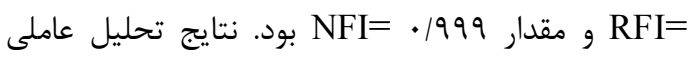
تاييدى نشان از كفايت كامل مدل و تاييد فيت مدل

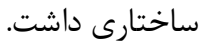
با استفاده از آزمون ضريب همبستخى بين جايگاه كنترل درونى سلامت با خودكارآمدى همبستخى مثبت وارتباط معنى دار مشاهده گرديد. همجنين بين زير مقياس باور به

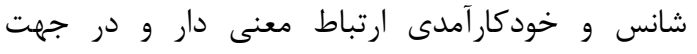
معكوس مشاهده گرديد. (جدول r)

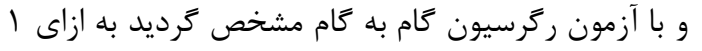

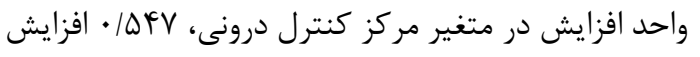
در متغير خودكار آمدى مشاهده گرديده است. (جدول أ)
نتيجه پايايى مقياس خودكارآمدى، با استفاده از آلفاى كرون باخ • • • به دست آمد و در تست باز آزمون اين

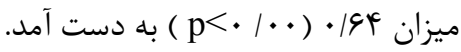
در روايى محتوى، نمره CVI مقياس خودكار آمدى در اين مطالعه با كمك يانل خبر گان • إ به دست آمد.كه نشان دهنده روايى محتوى بسيار عالى از نظر كمى مى باشد. و در خصوص روايى سازه، نتايج تحليل عاملى تاييدى مدل

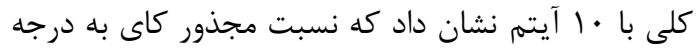

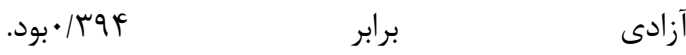
$\left(\frac{x^{2}}{d f}=\frac{1.977}{5}=0.395, P_{\text {value }}=0.852\right)$ و همجنين مقدار I RMSEA > + إصله اطمينان 


\begin{tabular}{|c|c|c|c|c|c|}
\hline \multirow[b]{2}{*}{ P-value } & \multirow[b]{2}{*}{ مقدار آماره تى } & \multirow[b]{2}{*}{ ضريب استاندارد } & \multicolumn{2}{|c|}{ ضرايب غير استاندارد } & \\
\hline & & & انحراف استاندارد & ضريب & \\
\hline $.1 \cdot 11$ & $T / \Delta \wedge V$ & & $9 / 94 \mid$ & $\mid V / 9 \Delta \Lambda$ & مقدار ثابت \\
\hline $1 \cdot 19$ & $T / F T$. & .1199 &.$/ T T \Delta$ &.$\Delta Q Y F$ & ميانگين باور درونى \\
\hline
\end{tabular}

از ديخر نتايج اين مطالعه ميانگين نمرات IHLC,CHLC,PHLC ميانغين نمره اينترنال و كمترين امتياز مربوط ميانگين

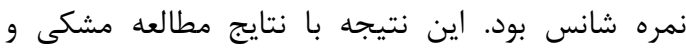

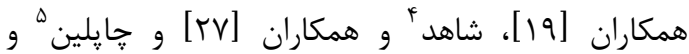

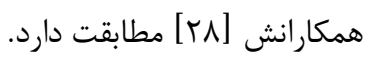

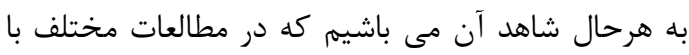

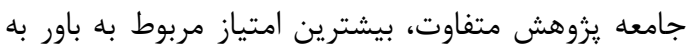

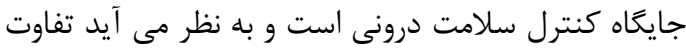
بين نمرات زير مقياس ها جهت قضاوت و نتيجه كيرى از اهميت بيشترى برخوردار باشد، زيرا در اين مطالعه تفاوت امتياز بسيار كمى بين IHLC و PHLC وجود داشت، آنجنان كه مى توان كَفت شركت كنندكان در اين مطان اعتقاد يكسانى به IHLC و IHLC كه اين تفاوت امتياز بين ميانكَين امتياز IHLC و PHLC در مطالعه مشكى بيشتر مى باشد و در مطالعه شاهد ميانغين امتياز PHLCوCHLC به يكديخر بسيار نزديكتر مى باشد تا حدى كه مى توان قضاوت نمود شركت

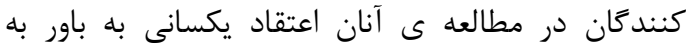

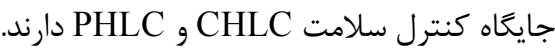
همجنين در مطالعه حاضر، بين CHLC با متغيرهاى سن و تحصيلات رابطه معنى دارى مشاهده گرديد. در واقع داصن زنان باسنين بالاتر اعتقاد بيشترى به محوريت شانس بانس دانه عنوان جايخاه كنترل سلامت نسبت به جوانتر ها داشتند.

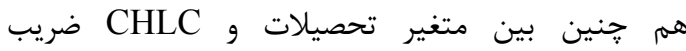

\section{4 -Shahed}

5 - chaplin
دراين مطالعه با استفاده از تحليل عاملى تاييدى

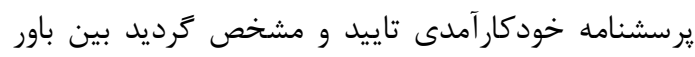

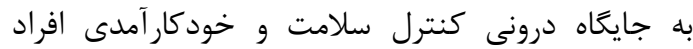
ارتباط وجود دارد. به كونه اي كه نتايج نشان دادند به ازئاي ا واحد افزايش در متغير مركز كنترل درونى، افزايش در متغير خودكار آمدى مشاهده كرديده است.

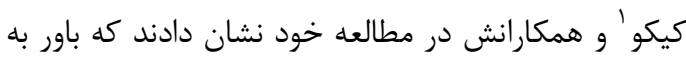

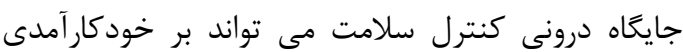

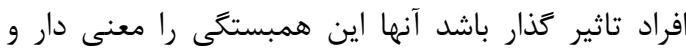

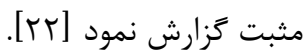

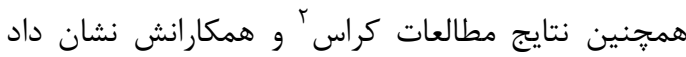
افراد با خودكارآمدى بيشتر، وضعيت سلامتى بهترى داشته اند. در اين مطالعه بين مركز بيرونى سلامت با بادئ

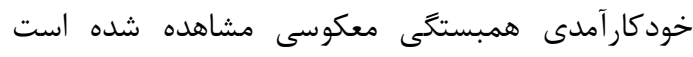
[rr] از طرف ديخر در اين مطالعه مشخص گرديد بين باور به

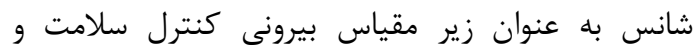
خودكارآمدى همبستكى منفى وجود دارئ دارد كه اين نتيجه

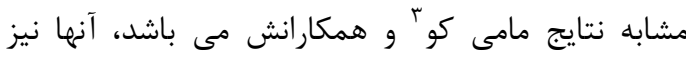

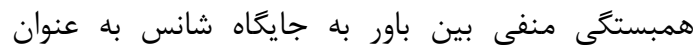

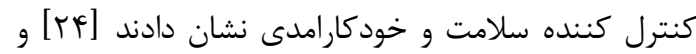
در بعضى از مطالعات ارتباط معنى دارى را بين جايخاه

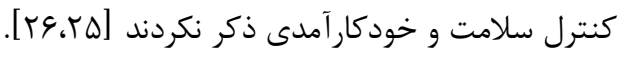

1 -Keiko

2 -Cross

3 -Mamiko 
يِيشنهاد مى گردد در مطالعات بعدى از مردان نيز به عنوان شركت كنندگان در مطالعه دعوت گردد. نتيجه كَيرى بين باور به مركز درونى كنترل سلامت و خودكارآمدى نام

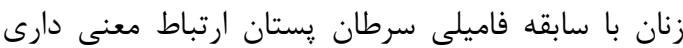
وجود دارد. لذا تقويت باور به مركز درونى سلامت مى تواند بر ارتقائ خودكارآهدى افراد تاثير كذار باشد.

تشكر و قدردانى

اين مطالعه قسمتى از קِايان نامه مصوب دكترى آموزش

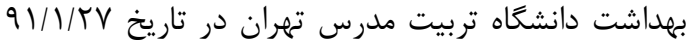

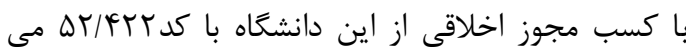

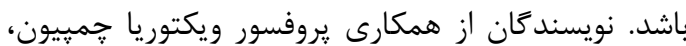
دكتر مهلى مشكى و همجنين تمامى زنان شركت كنينده در مطالعه تشكر مى نمايند.

همبستگى منفى مشاهده گَرديد، به گَونه اي كه افراد با ميزان تحصيلات بالاتر اعتقاد كمترى به محوريت شانس همانس به عنوان مركز كنترل سلامت داشتند. كه با ياره اي از إنائ

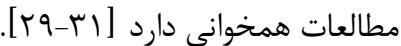
از آن جايى كه درمطالعه جارى، زنان جوان تر تحصيلات

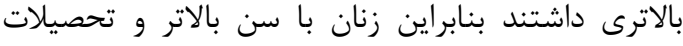
كمتر بيشتر به CHLC اعتقاد داشتند. در هر صورت ميزان تحصيلات و به دنبال آن افزايش

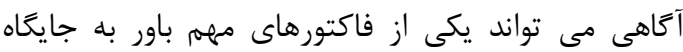

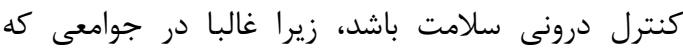
ميزان تحصيلات بالاتر است آكاهى نسبت بهادئ موضوع نيز بيشتر به جشم مى خورد و همين مسئله مى تواند روى

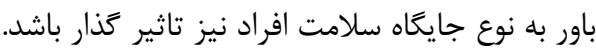
از طرف ديخربين ميزان تحصيلات و خودكارآمدى نيز

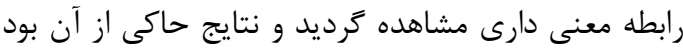
كه زنان با تحصيلات بالاتر خودكارآمدى بيشترى داشتند.

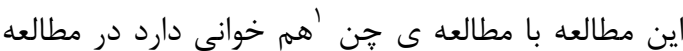

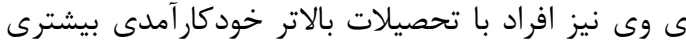

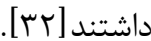

همجنين بين تحصيلات و اعتقاد به مركز بيرونى سلامت

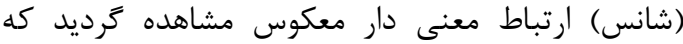
مطالعه جن و همكاران نيز همين يافته را تاييد كرده است معاط مردي $[r r]$

اما جندين محدوديت در مطالعه حاضر وجود داشته است.

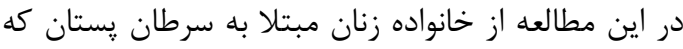
زنده بودند به عنوان شركت كنندكان در مطالعه استفاده شد زيرا دسترسى به افراد خانواده مبتلايان به اين بيمارى

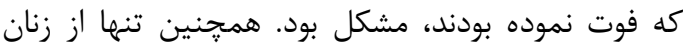

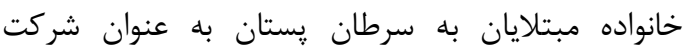
كنندكان در مطالعه استفاده شد زيرا زنان بيش از مردان بان بان

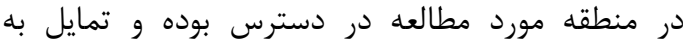
همكارى بيشترى نسبت به مردان در مطالعه داشتند. از نقاط قوت اين مطالعه نيز مى توان به انتخاب جامعه يزوهش در معرض خطر ابتلا به بيمارى (سابقه بيمارى

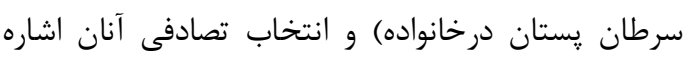
نمود.

\section{1 -Chen}




\section{References}

1. American Cancer Society,(2013), Cancer Facts and Figures. Atlanta, Ga, Available online, Last accessed : 4 January 2013.

2. Homaei F,Center for Cancer Research.aviable

at:http://www.mums.ac.ir/cancer/fa. Last Accessed 12 Jan 2012[Persian].

3. Mousavi SM, Montazeri A, Mohagheghi MA, Jarrahi AM, Harirchi I, Najafi M, "et al", Breast cancer in Iran: An epidemiological review, J Breast, 2007;13:383-91[Persian].

4. WHO Media centre. available at: http://www.who.int/mediacentre/factsheets/fs2

97/en/,Fact sheet N²97, Reviewed January 2013.

5. Hellquist B, Duffy SW, Abdsaleh S, "et al", Effectiveness of population-based service screening with mammography for women ages 40 to 49 years: evaluation of the Swedish Mammography Screening in Young Women (SCRY) cohort, Cancer J, 2011; 117(4): 71422.

6. Stephanie, R. Cigarette smoking, Obesity ,physical activity and alcohol use as predicators of chemoprevention adherence in the national surgical adjuvant breast and bowel project plbreast cancer prevention trial, J Cancer prevention research, 2011; 4:139.

7. Champion V, Monahan P, Springston J, "et al", Measuring Mammography and Breast Cancer Beliefs in African American Women, J Health Psychology, 2008 ; 13(6): 827-37.

8. Williams-Piehota P, Schneider T, Pizarro J, Movad L, Salovery P, Matching health messages to locus of control beliefs for promotioning mammography Utilization, J psychology and Health, 2004;(19): 407-23.

9. Rotter J.B,Social learning and clinical psychology, New York: Prentice-Hall, 1954.

10.Wallston B.S, Wallston K. A, Kaplan G. D, Maides, S. A. The development and validation of the health related locus of control (HLC) scale, Journal of Consulting and Clinical Psychology, 1976; 44(4), 580- 5

11.Luszcynska A, Schwarzer R, Wallston KA, Multidimensional health locus of control: Comments on the construct and its measurement, J Health Psychology, 2005;10:633- 42

12.Kelly PA, Kallen MA, Suarez-Almazor ME, A combined-method psychometric analysis recommended modification of the multidimensional health locus of control scales, J Clin Epidemiology, 2007;60: 440-7

13. Bandura A, Social foundations of thought and action, Englewood Cliffs, NJ: Prentice Hall, 1986.

14.Bandura A , Social cognitive theory of self-regulation, Organizational Behavior \& Human Decision Processes, 1991;50: 248-287 15.Champion VL, Sugg Skinner C, Menon U, Development of a Self-Efficacy Scale for Mammography, J Research in Nursing \&Health, 2005;329-336

16. Russell KM, Perkins SM, Zollinger TW, Champion VL, Sociocultural context of mammography screening use, Oncol Nurs Forum, 2006;33:105-112.

17.Tolma EL, Reininger BM, Evans A, Ureda J, Examining the theory of planned Behavior and the construct of the self-efficacy to predict mammography intention j Health Education Behavior, 2006,33(2): 233- 51

18.Power Calculations for Matched CaseControl Studies', Biometrics, Volume 44, pages $1157-1168$

19.Marc A, Fritiz, Speroff L, Clinical Gynecologic Endocrinology and Infertility $2011.8^{\text {th }}$ ed.

20.Moshki M, Ghofranipour F, Hajizadeh E, Azadfallah P, Validity and reliability of the multidimensional health locus of control scale for college students, BMC Public Health, 2007, 7:295[Persian]

21.Hajizadeh E, Asghari M, Statistical Methods and Analyses In Health and Biosciences, A Research Methodological Approach, Tehran: Jahade daneshkahi ; 2012. $1^{\text {th }}$ ed[Persian].

22. Tabachnick G.B. , Fidell S.L, Using Multivariate Statistics Pearson, Boston, 2007, $5^{\text {th }}$ ed.

23.Keiko T, Yoshiko F, Masafumi $\mathrm{K}$, Kenichi T, Relationships between Spirituality, Health Self-efficacy and Health Locus of Control in the Elderly, Kawasaki journal of medical welfare, 2009; 14(2): 81-91

24.Cross MJ, March LM, Lapsley HM, Byrne E, Brooks PM, Patient self-efficacy and health locus of control: relationships with health status and arthritis-related expenditure, Rheumatology, 2006; 45(1):92-6

25.Mamiko Y, Akimitsu T, Hiroshi T, SelfEfficacy and Health Locus of Control in 
Diabetic Patients, J Kobe Daigaku Igakubu Hoken Gakka Kiyo, 1998;14;101- 8

26. Olga Prusak, Relationships Among Locus of Control, Perceived Self-efficacy and Medication Adherence in Members of DoubleTrouble in Recovery Or Dual Recovery Anonymous Self-help Groups, ProQuest Dissertations and Theses 2007, Capella university .

27.Dawn Samuel Dublin, The relationship between self-efficacy and locus of control and employment duration of women on Temporary Assistance to Needy Families, ProQuest Dissertations and Theses 2009, Adelphi university, school of social work.

28. Shahed S, Health Locus of Control, Health Beliefs, and Health Related Behaviors: A Study of Urban Females, (Dissertation for the Degree of Doctor of Philosophy), 2011, University of the Punjab, Lahore.

29.Chaplin WF, Davidson K, Sparrow V, Stuhr J, Van Roosmalen E, Wallston KA, A Structural Evaluation of the Expanded Multidimensional Health Locus of Control Scale with a Diverse Sample of
Caucasian/European, Native, and Black Canadian Women, Journal of Health Psychology, 2001; 6,447-55

30.Kuwahara A, Nishino Y, Ohkubo T, Tsuji I, Hisamichi S, Hosokawa T, Reliability and validity of the multidimensional health locus of control scale in Japan: relationship with demographic factors and health- related behavior, Tohoku J.Exp. Med, 2004; 203(1): 34-45

31.Rodriguez-Rosero J.E, Ferriani M.G, Dela Coleta M.F, (2002), Multidimensional health locus of control scale - MHLC: validation study. Rev Lat Am Enfermagem, 2002; 10(2): 179-84

32. Wallston K. A, Wallston B. S, DeVe llis R. F, (1978) , Development of the Multidimensional Health Locus of Control (MHLC) scales, Health Education Mono graphs, 1978; 6(2): 160-170

33. Chen SH, Acton G, Shao JH, Relationships among nutritional self-efficacy, health locus of control and nutritional status in older Taiwanese adults, J Clin Nurs, 2010 Aug;19(15-16):2117-27 


\title{
Survey the type of health locus of control and relationship with self efficacy in women with Family history of breast cancer
}

\author{
Hashemian $M^{1}$, Aminshokravi $F^{2}$,Hidarnia $A^{3}$, Lamyian $M^{4}$, Hassanpur $K^{5}$, Akaberi $A^{6}$ \\ ${ }^{1}$ Phd candidate of Health education, School of Medical Sciences, Tarbiat Modares University, Tehran, Iran \\ ${ }^{2}$ Assistant Professor of Health education, School of Medical Sciences, Tarbiat Modares University, Tehran, Iran \\ ${ }^{3}$ Associate Professor of Health education, Department of Health education,School of Medical Sciences, \\ Tarbiat Modares University, Tehran,Iran \\ ${ }^{4}$ Assistant Professor Medical Sciences Faculty, Tarbiat Modares University, Tehran, Iran \\ 5Associate Professor of School of Medical Sciences Sabzevar University, Tehran, Iran. \\ ${ }^{6}$ Lecturer of Biostatistics, Addiction and Behavioral Sciences Research Center, North Khorasan University of \\ Medical Sciences, Bojnurd, Iran.
}

\author{
*Corresponding Author: \\ School of Medical Sciences, \\ Tarbiat Modares University, \\ Tehran, Iran \\ E-mail: \\ Aminsh_f@modares.ac.ir
}

Submitted:30 Oct 2013

Revised:20 Jan 2014

Accepted: 26 Jan 2014

\section{Abstract}

Background \& Objective: Self efficacy emphasizes on individual belief about behavior, and belief to this point that to what extent health control is voluntary can be as appropriate health behavior. The purpose of this study is determination of the effect of belief in internal health locus of control on the efficacy rate for doing mammography in women.

Materials \& Methods: The cross sectional study was done in city of sabzevar in 1391. The study consisted of all Women with family history of breast cancer. With simple random sampling and during interview, 150 eligible women were enrolled to this study. Instrument validity through face and content validity and the construct validity. Further, the instruments' reliability was assessed using Cronbach's alpha and retest reliability. SPSS software version 21 was used for the analysis of the data. Further, AMOS software version 16 was used for the construct validity self efficacy scale. Moreover, pearson's and stepwise regression tests were applied to study theoretical relationships. A statistically significant test was defined as a P-value below 0.05 in the study.

Results: The mean age of the sample was 44.48 (6.88). The highest score was related to internal health locus of control with 30.65(3.13). A statistically significant relationship was found between self efficacy and internal health locus of control, $(P<$ $0.01)$. Step wise regression showed with one unit increase in internal health locus of control increase 0.534 in self efficacy variable.

Conclusion Significant relation is between internal health locus of control and self efficacy.

Keywords: Breast cancer, Health Locus of Control, Self efficacy Mammography 